\begin{tabular}{|c|c|c|}
\hline BIODIK & $\begin{array}{c}\text { BIODIK: Jurnal IImiah Pendidikan Biologi } \\
\text { ISSN 2580-0922 (online), ISSN 2460-2612 (print) } \\
\text { Volume 6, Nomor 04, Tahun 2020, Hal. 434-441 } \\
\text { Available online at: } \\
\text { https://online-journal.unja.ac.id/biodik }\end{array}$ & BIODIK \\
\hline
\end{tabular}

Research Article

OPEN ACCESS

\title{
Analisis Kualitas Struktur Lembar Kerja Peserta Didik pada Materi Struktur Tulang Berbasis Diagram Vee
}

\section{(An Analysis of the Quality of Bone Structure Student Worksheets Based on the Vee Diagram)}

\author{
Resta Istawa, Bambang Supriatno, Sri Anggraeni \\ Universitas Pendidikan Indonesia \\ Jalan Dr. Setiabudi No. 229, Bandung 40154, Indonesia \\ ${ }^{*}$ Coressponding Authors: restaistawa3017@gmail.com
}

\begin{tabular}{|c|c|}
\hline Informasi Artikel & ABSTRACT \\
\hline $\begin{array}{l}\text { Submit: } 04-06-2020 \\
\text { Diterima: } 15-10-2020 \\
\text { Dipublikasikan: } 17-12-2020\end{array}$ & $\begin{array}{l}\text { Student worksheets used as practical guide in laboratory activities will highly } \\
\text { determine the achievement of learning objectives required by the curriculum. } \\
\text { However, the structure of student worksheet as a laboratory activity design still } \\
\text { should be improved. This study aims to explain the results of the analysis of bone } \\
\text { structure student worksheets used in learning with National Curriculum } 2006 \text { and } \\
\text { 2013. The research method used was qualitative descriptive method and the sample } \\
\text { were } 6 \text { student worksheets. The student worksheets were used as practical guide in } \\
\text { laboratory activities in national senior high school in Garut Regency and selected } \\
\text { using a total sampling technique. The research instruments used were completeness } \\
\text { of the student worksheets components rubric and scoring rubric of the components of } \\
\text { Vee Diagram adapted from Novak \& Gowin (1984). The results showed that the bone } \\
\text { structure student worksheets used in national senior high school in Garut Regency } \\
\text { still have incomplete Vee Diagram components and the components appear still do } \\
\text { not have a maximum score. } \\
\text { Keywords: : Student Worksheet, Vee Diagram, Bone Structure }\end{array}$ \\
\hline Penerbit & ABSTRAK \\
\hline $\begin{array}{l}\text { Program Studi Pendidikan } \\
\text { Biologi, Fakultas Keguruan dan } \\
\text { IImu Pendidikan, Universitas } \\
\text { Jambi }\end{array}$ & $\begin{array}{l}\text { Lembar Kerja Peserta Didik (LKPD) yang digunakan sebagai panduan kegiatan } \\
\text { laboratorium akan menentukan ketercapaian tujuan kegiatan laboratorium dan tujuan } \\
\text { pembelajaran yang dituntut oleh kurikulum. Namun, struktur LKPD yang memuat } \\
\text { desain kegiatan laboratorium sekolah nyatanya masih jauh dari yang diharapkan. } \\
\text { Penelitian ini bertujuan untuk menjelaskan tentang hasil analisis terhadap LKPD } \\
\text { Struktur Tulang yang digunakan pada saat pembelajaran dengan Kurikulum Tingkat } \\
\text { Satuan Pendidikan (KTSP) } 2006 \text { dan Kurikulum 2013. Metode penelitian yang } \\
\text { digunakan adalah metode deskriptif kualitatif dengan sampel penelitian berjumlah } 6 \\
\text { LKPD. Sampel LKPD tersebut digunakan sebagai petunjuk kegiatan laboratorium di } \\
\text { SMA Negeri di Kabupaten Garut dan dipilih dengan menggunakan teknik total } \\
\text { sampling. Instrumen penelitian yang digunakan untuk menilai kualitas struktur LKPD } \\
\text { adalah rubrik kelengkapan komponen LKPD dan rubrik penskoran komponen LKPD } \\
\text { berdasarkan Diagram Vee yang diadaptasi dari Novak \& Gowin (1984). Hasil } \\
\text { penelitian menunjukkan bahwa LKPD Struktur Tulang yang digunakan di SMA Negeri } \\
\text { di Kabupaten Garut belum memiliki komponen Diagram Vee lengkap dan komponen- } \\
\text { komponen yang ada belum mencapai skor maksimum. } \\
\text { Katakunci: Lembar Kerja Peserta Didik (LKPD), Diagram Vee, Struktur Tulang }\end{array}$ \\
\hline
\end{tabular}

This BIODIK : Jurnal IImiah Pendidikan Biologi is licensed under a CC BY-NC-SA (Creative Commons Attribution-ShareAlike 4.0 International License) 


\section{PENDAHULUAN}

Dalam pendidikan sains, kegiatan laboratorium merupakan bagian integral dari kegiatan belajar mengajar, termasuk biologi (Rustaman, 2005). Secara khusus, Society of Biology (2010) mengemukakan bahwa kegiatan laboratorium biologi penting untuk memberikan pengalaman dan meningkatkan pemahaman terhadap sistem kehidupan yang kompleks. Kegiatan laboratorium juga mampu membantu peserta didik untuk memahami konsep ilmiah dengan lebih jelas dan meningkatkan hasil belajar peserta didik (Festile, 2017; Koirala, 2019). Kegiatan laboratorium dapat membantu peserta didik untuk menghubungkan dua domain pengetahuan, yaitu domain objek nyata yang dapat diamati (domain of real objects) dengan domain ide (domain of ideas) (Millar, 2001). Oleh karenanya, kegiatan laboratorium perlu didesain dengan tepat agar peserta didik mampu mencapai tujuan dari kegiatan laboratorium yang mereka lakukan.

Kegiatan laboratorium perlu dirancang agar peserta didik dapat mengalami belajar bermakna dengan membantu mereka menghubungkan pengetahuan baru dengan pengetahuan lama yang dimilikinya (Novak \& Gowin, 1984). Menurut Novak \& Gowin (1984), idealnya pengetahuan yang dibentuk melalui kegiatan laboratorium mengikuti struktur Diagram Vee dengan melibatkan pertanyaan fokus yang relevan dengan objek, peristiwa utama, pencatatan dan transformasi, serta keterlibatan konsep, prinsip dan teori yang relevan dalam menjelaskan peristiwa yang terjadi. Namun, kegiatan laboratorium di sekolah yang umumnya didesain dalam bentuk Lembar Kerja Peserta Didik (LKPD) memiliki kualitas yang masih jauh dari yang diharapkan. Jika ditinjau dari segi strukturnya, masih banyak LKPD yang belum memiliki komponen Diagram Vee lengkap dan kualitas setiap komponennya pun beragam (Nadia et al., 2020; Ramadhayanti et al., 2020; Wahidah et al., 2018).

Dari sisi konseptual, prosedural, maupun konstruksi pengetahuan, LKPD yang digunakan saat ini juga belum memenuhi ketiga aspek tersebut. Berdasarkan hasil penelitian sebelumnya yang dilakukan oleh Supriatno (2009), hanya 24\% Desain Kegiatan Laboratorium (DKL) yang dapat dikerjakan dengan hasil sesuai prosedur dan tuntas dari segi analisis data dan penarikan kesimpulan. Lebih lanjut dipaparkan bahwa DKL tersebut memiliki tujuan praktikum yang lebih banyak menekankan aspek kognitif daripada aspek psikomotor, menggunakan pendekatan deduktif dengan model ekspositori, prosedur praktikum yang tidak terstruktur dan membingungkan, serta pemilihan materi yang tidak mempertimbangkan esensi, kesesuaian, kedalaman, dan kompleksitasnya.

Berdasarkan sejumlah permasalahan pada LKPD yang telah dipaparkan sebelumnya, maka diperlukan analisis lebih lanjut dan mendalam terhadap LKPD yang saat ini masih sering digunakan di sekolah. LKPD Struktur Tulang sebagai pedoman praktikum yang sering dipilih oleh guru untuk membelajarkan tentang struktur penyusun tulang mendorong peneliti untuk menganalisis kualitas dan kelayakannya untuk digunakan oleh peserta didik SMA. Analisis ini didasarkan pada kelengkapan dan kualitas komponen Diagram Vee, sebuah heuristik yang terdiri dari 
pertanyaan fokus, objek/ peristiwa, teori/ prinsip/ konsep, catatan/ transformasi, dan klaim pengetahuan.

\section{METODE PENELITIAN}

Metode penelitian yang digunakan dalam penelitian ini adalah metode deskriptif kualitatif yang bertujuan untuk menggambarkan fenomena-fenomena yang ditemukan secara mendalam (Sugiyono, 2012). Penelitian ini diupayakan mampu memberikan gambaran tentang keadaan Lembar Kerja Peserta Didik (LKPD) praktikum biologi pada materi struktur tulang yang digunakan di SMA Negeri di Kabupaten Garut, Provinsi Jawa Barat. Sampel yang digunakan dalam penelitian ini dipilih dari buku paket biologi SMA yang diterbitkan oleh dua penerbit berbeda dengan menggunakan teknik total sampling dan berjumlah 6 LKPD. Dari 6 LKPD tersebut, 4 LKPD diantaranya digunakan pada saat pembelajaran dengan Kurikulum Tingkat Satuan Pendidikan (KTSP) 2006 dan 2 LKPD lainnya digunakan pada saat pembelajaran dengan Kurikulum 2013.

Instrumen penelitian yang digunakan untuk menilai kualitas struktur LKPD adalah rubrik kelengkapan komponen LKPD dan rubrik penskoran komponen LKPD berdasarkan Diagram Vee yang diadaptasi dari Novak \& Gowin (1984). Diagram Vee dipilih karena komponen-komponennya dapat dijadikan sebagai rambu-rambu untuk membantu peserta didik memahami makna dari suatu kegiatan laboratorium dan membantu mereka membentuk pengetahuannya sendiri. Kedua rubrik penskoran tersebut menilai kualitas struktur LKPD yang ditinjau dari kelengkapan dan kualitas komponen-komponennya yang terdiri dari komponen pertanyaan fokus (focus questions), objek/ peristiwa (objects/ events), teori/ prinsip/ konsep (theories/ principles/ concepts), catatan/ transformasi (records/ transformations), dan klaim pengetahuan (knowledge claim). Data yang diperoleh dari rubrik penskoran komponen LKPD kemudian diubah ke dalam bentuk persentase (\%) untuk mengetahui ketercapaian setiap LKPD terhadap kriteria komponen LKPD berdasarkan Diagram Vee dan kualitas setiap komponen dari seluruh LKPD yang dianalisis.

\section{HASIL DAN PEMBAHASAN}

\section{Analisis Keberadaan Komponen Diagram Vee di LKPD Struktur Tulang}

Komponen Diagram Vee terdiri dari pertanyaan fokus, objek/ peristiwa, teori/ prinsip/ konsep, catatan/ transformasi, dan klaim pengetahuan. Berdasarkan data pada Tabel 1, terdapat sebagian Lembar Kerja Peserta Didik (LKPD) KTSP 2006 yang tidak memiliki komponen Diagram Vee lengkap. 
Tabel 1. Analisis Keberadaan Komponen Diagram Vee di LKPD Struktur Tulang

\begin{tabular}{llcccc}
\hline \multirow{2}{*}{ No. } & \multirow{2}{*}{$\begin{array}{c}\text { Komponen Diagram } \\
\text { Vee }\end{array}$} & \multicolumn{2}{c}{ KTSP 2006 } & \multicolumn{2}{c}{ Kurikulum 2013 } \\
\cline { 3 - 6 } & & Ada & $\begin{array}{c}\text { Tidak } \\
\text { Ada }\end{array}$ & Ada & $\begin{array}{c}\text { Tidak } \\
\text { Ada }\end{array}$ \\
\hline 1. & Pertanyaan fokus & 3 LKPD & 1 LKPD & 2 LKPD & - \\
2. & Objek/ peristiwa & 4 LKPD & - & 2 LKPD & - \\
3. & Teori/ prinsip/ konsep & 4 LKPD & - & 2 LKPD & - \\
4. & Catatan/ transformasi & 1 LKPD & 3 LKPD & 2 LKPD & - \\
5. & Klaim pengetahuan & 4 LKPD & - & 2 LKPD & - \\
\hline
\end{tabular}

Beberapa LKPD tersebut masih belum memiliki komponen pertanyaan fokus dan catatan/ transformasi. Temuan ini bersesuaian dengan penelitian terdahulu yang dilakukan oleh Ramadhayanti et al. (2020) yang menyatakan bahwa sebagian LKPD Indra Pengecap juga tidak memiliki komponen Diagram Vee lengkap. Ketidaklengkapan komponen Diagram Vee dalam sebuah LKPD ini dapat menyebabkan terganggunya proses pembentukan pengetahuan baru pada diri peserta didik. Hal ini terjadi karena komponen-komponen Diagram Vee tersebut saling mendukung satu sama lain untuk membantu peserta didik mengonstruksi pengetahuan barunya dari sebuah kegiatan laboratorium (Novak \& Gowin, 1984).

\section{Analisis Kualitas Komponen Diagram Vee di LKPD Struktur Tulang}

Setelah melakukan analisis terhadap keberadaan komponen-komponen Diagram Vee, dilakukan pula penskoran terhadap setiap komponen Diagram Vee tersebut. Untuk komponen pertanyaan fokus dan objek/ peristiwa, skor maksimumnya adalah 3. Sementara, untuk komponen teori/ prinsip/ konsep, catatan/ transformasi, dan klaim pengetahuan, skor maksimumnya adalah 4. Berdasarkan data pada Tabel 2, hanya 4 LKPD Struktur Tulang yang mampu memperoleh setengah dari skor maksimum komponen Diagram Vee (skor maksimum = 18). 2 LKPD lainnya hanya mampu memperoleh skor minimum di hampir semua komponen Diagram Vee.

Tabel 2. Analisis Kualitas Komponen Diagram Vee di LKPD Struktur Tulang

\begin{tabular}{|c|c|c|c|c|c|c|c|}
\hline \multirow[b]{2}{*}{$\begin{array}{l}\text { Kode } \\
\text { LKPD }\end{array}$} & \multicolumn{5}{|c|}{ Skor Komponen Diagram Vee } & \multirow[b]{2}{*}{$\begin{array}{l}\text { Skor } \\
\text { Total }\end{array}$} & \multirow[b]{2}{*}{$\begin{array}{c}\text { Capaian } \\
\text { Kriteria } \\
\text { Diagram } \\
\text { Vee (\%) }\end{array}$} \\
\hline & $\begin{array}{l}\text { Pertanyaan } \\
\text { Fokus }\end{array}$ & $\begin{array}{l}\text { Objek/ } \\
\text { Peristiwa }\end{array}$ & $\begin{array}{c}\text { Teori/ } \\
\text { Prinsip/ } \\
\text { Konsep }\end{array}$ & $\begin{array}{l}\text { Catatan/ } \\
\text { Transformasi }\end{array}$ & $\begin{array}{c}\text { Klaim } \\
\text { Pengetahuan }\end{array}$ & & \\
\hline LKPD & & & & & & & \\
\hline $\begin{array}{l}117 \\
\text { LKPD }\end{array}$ & 2 & 2 & 3 & 2 & 2 & 11 & 61.1 \\
\hline $\begin{array}{l}218 \\
\text { LKPD }\end{array}$ & 3 & 3 & 3 & 3 & 3 & 15 & 83.3 \\
\hline $\begin{array}{l}309 \\
\text { LKPD }\end{array}$ & 2 & 3 & 4 & 2 & 3 & 14 & 77.8 \\
\hline $\begin{array}{l}409 \\
\text { LKPD }\end{array}$ & 1 & 2 & 2 & 0 & 1 & 6 & 33.3 \\
\hline $\begin{array}{l}509 \\
\text { LKPD }\end{array}$ & 0 & 1 & 1 & 0 & 1 & 3 & 16.7 \\
\hline 611 & 3 & 2 & 3 & 0 & 2 & 10 & 55.6 \\
\hline
\end{tabular}


Berdasarkan data pada Tabel 3, persentase (\%) setiap skor untuk masingmasing komponen Diagram Vee bervariasi. Skor maksimum hanya dicapai oleh beberapa LKPD Struktur Tulang pada komponen pertanyaan fokus, objek/ peristiwa, dan teori/ prinsip/ konsep. Untuk komponen pertanyaan fokus, persentase skor 2 dan skor $3(33 \%)$ adalah yang tertinggi. Temuan ini menunjukkan bahwa LKPD tersebut memiliki pertanyaan fokus yang secara jelas dapat diidentifikasi, termasuk konsep yang akan digunakan serta menunjukkan peristiwa utama dan objek yang menyertainya. Pertanyaan fokus yang dinyatakan secara jelas dan akurat dalam sebuah LKPD dapat membuat kegiatan laboratorium berjalan efektif (Millar \& Abrahams, 2009). Pertanyaan fokus juga harus disusun secara tepat untuk mendorong dan mengarahkan perhatian peserta didik pada objek atau peristiwa yang harus diamati sehingga terbentuklah need to know (Supriatno, 2013).

Untuk komponen objek/ peristiwa, separuh dari sampel LKPD Struktur Tulang yang dianalisis memperoleh skor 2. Hal ini menandakan bahwa LKPD tersebut memiliki objek dan peristiwa utama yang dapat diidentifikasi, serta konsisten dengan pertanyaan fokus. Objek/ peristiwa yang diamati oleh peserta didik saat melakukan kegiatan laboratorium adalah sumber dari kegiatan pencatatan dan transformasi, serta awal dari proses pembentukan pengetahuan baru (Novak \& Gowin, 1984). Oleh karenanya, jika objek/ peristiwa yang seharusnya diamati oleh peserta didik tidak muncul atau sulit diamati, maka catatan dan transformasi yang dilakukan oleh peserta didik menjadi tidak tepat dan dapat menimbulkan miskonsepsi di diri peserta didik. Kegiatan laboratorium dalam LKPD harus mampu membantu peserta didik untuk mengobservasi objek/ peristiwa yang seharusnya diamati, mengarahkan peserta didik untuk mengobservasi dengan lebih cermat dan teliti, dan menjembatani pembentukan pengetahuan baru pada domain ide (Millar, 2001).

Tabel 3. Persentase Setiap Skor Komponen Diagram Vee

\begin{tabular}{ccc}
\hline Komponen Diagram vee & Skor & $\begin{array}{c}\text { Persentase } \\
(\%)\end{array}$ \\
\hline Pertayaan Fokus & 0 & 17 \\
& 1 & 17 \\
Objek/ Peristiwa & 2 & 33 \\
& 3 & 33 \\
& 0 & 0 \\
Teori/ Prinsip/ Konsep & 1 & 17 \\
& 2 & 50 \\
& 3 & 33 \\
& 0 & 0 \\
& 1 & 17 \\
& 2 & 17 \\
& 3 & 50 \\
& 4 & 17
\end{tabular}




\begin{tabular}{ccc}
\hline Komponen Diagram vee & Skor & $\begin{array}{c}\text { Persentase } \\
(\%)\end{array}$ \\
\hline Catatan/ Transformasi & 0 & 50 \\
& 1 & 0 \\
Klaim Pengetahuan & 3 & 33 \\
& 4 & 17 \\
& 0 & 0 \\
& 1 & 33 \\
& 2 & 33 \\
& 3 & 33 \\
4 & 0 \\
\hline
\end{tabular}

Untuk komponen teori/ prinsip/ konsep, separuh dari sampel LKPD Struktur Tulang yang dianalisis memperoleh skor 3 , yang artinya LKPD tersebut memiliki konsep dan prinsip, atau sebuah teori yang dapat diidentifikasi. Teori, prinsip, dan konsep dalam LKPD ini juga mendukung kegiatan pencatatan dan transformasi data sehingga data yang diperoleh tersebut mampu menunjang pembentukan klaim pengetahuan. Meski demikian, masih ditemukan LKPD yang tidak memuat bagian konseptual sama sekali atau hanya memuat sedikit konsep. Kondisi ini menyebabkan tidak adanya saling keterkaitan antara objek/ peristiwa yang diamati dengan proses berpikir peserta didik sehingga kegiatan laboratorium seringkali menjadi tidak bermakna (Novak \& Gowin, 1984). Kegiatan laboratorium dalam LKPD ini pun menjadi tidak efektif karena tidak dirancang agar mampu melibatkan aspek kognitif peserta didik untuk menjelaskan tentang objek/ peristiwa yang mereka amati (Millar, 2004).

Untuk komponen catatan/ transformasi, separuh dari sampel LKPD Struktur Tulang yang dianalisis memperoleh skor 0 . Hal ini menunjukkan bahwa LKPD tersebut tidak memiliki kegiatan pencatatan ataupun transformasi apapun yang dapat diidentifikasi. Padahal, kegiatan pencatatan dan transformasi tersebut berguna bagi peserta didik untuk menyusun klaim pengetahuan dan menjawab pertanyaan fokus (Novak \& Gowin, 1984). Jika peserta didik tidak diarahkan untuk melakukan kegiatan pencatatan dan transformasi data pada saat kegiatan laboratorium, maka klaim pengetahuan yang dibentuk bisa menjadi salah atau tidak relevan dengan sisi konseptual Vee. Selain itu, jika sebuah kegiatan laboratorium dalam LKPD tidak memiliki komponen catatan dan transformasi, maka pemahaman peserta didik terhadap kegiatan laboratorium tersebut menjadi kurang tergambar (Supriatno, 2013). Lebih lanjut dikemukakan bahwa kegiatan laboratorium tersebut juga kurang dapat meningkatkan self awareness peserta didik sehingga proses metakognitifnya untuk memahami dan memaknai hasil observasi tidak terfasilitasi.

Untuk klaim pengetahuan, persentase skor komponen Diagram Vee pada LKPD Struktur Tulang belum menunjukkan skor ideal (skor 4). Beberapa LKPD mengarahkan peserta didik untuk membuat klaim pengetahuan yang tidak konsisten 
dengan data atau objek/ peristiwa yang diamati. Temuan ini sejalan dengan penelitian sebelumnya yang dilakukan oleh Nadia et al., (2020) yang menyatakan bahwa konstruksi pengetahuan dari kegiatan laboratorium di LKPD Struktur dan Fungsi Jaringan Tumbuhan tidak dibentuk berdasarkan fakta. Hal ini terjadi karena pertanyaan praktikum yang ada hanya menanyakan tentang karakter objek/ peristiwa yang diamati dan tidak mengarah kepada pembentukan teori, prinsip, dan konsep untuk membentuk klaim pengetahuan. Padahal, klaim pengetahuan semestinya melibatkan perolehan konsep sebagai hasil inkuiri peserta didik untuk menjawab pertanyaan fokus (Calais, 2009).

\section{KESIMPULAN}

Secara umum, Lembar Kerja Peserta Didik (LKPD) Struktur Tulang yang digunakan di SMA Negeri di Kabupaten Garut belum sepenuhnya mengacu pada komponen-komponen Diagram Vee. Berdasarkan hasil analisis, beberapa LKPD tidak memiliki komponen pertanyaan fokus dan catatan/ transformasi. LKPD lainnya yang sudah memiliki komponen Diagram Vee lengkap, belum mencapai skor maksimum untuk setiap komponennya. Oleh karenanya, LKPD Struktur Tulang yang digunakan oleh peserta didik di SMA Negeri di Kabupaten Garut belum sempurna menunjang proses pembentukan pengetahuan. Agar kegiatan laboratorium pengamatan struktur tulang dapat menunjang pembentukan pengetahuan peserta didik dan sesuai dengan tujuan kegiatan laboratorium, maka disarankan untuk melakukan rekonstruksi terhadap LKPD tersebut.

\section{DAFTAR PUSTAKA}

Calais, G. J. (2009). The Vee Diagram as a Problem Solving Strategy: Content Area Reading/Writing Implications. National Forum Teacher Education Journal, 19(3), $1-8$.

Festile, R. M. (2017). The Influence of Practical Work in the Teaching and Learning of Acids, Bases, and Neutrals in Natural Sciences [University of the Western Cape]. http://hdl.handle.net/11394/5921

Koirala, K. P. (2019). Effectiveness of Practical Work on Students' Achievement in Science at Secondary Level in Gorkha District Nepal. Journal of Advances in Education Research, 4(4), 139-147. https://doi.org/10.22606/jaer.2019.44001

Millar, R. (2001). Teaching and Learning Science Through Practical Work.

Millar, R. (2004). The Role of Practical Work in The Teaching and Learning of Science.

Millar, R., \& Abrahams, I. (2009). Practical Work: Making It More Effective. School Science Review, 91(334), 59-64.

Nadia, Supriatno, B., \& Anggraeni, S. (2020). Analisis dan Rekonstruksi Komponen Penyusun Lembar Kerja Peserta Didik Struktur dan Fungsi Jaringan Tumbuhan. BIODIK: Jurnal IImiah Pendidikan Biologi, 6(2), 187-199.

Novak, J. D., \& Gowin, D. B. (1984). Learning How to Learn. Cambridge University. Ramadhayanti, Anggraeni, S., \& Supriatno, B. (2020). Analisis dan Rekonstruksi Lembar Kerja Peserta Didik Indra Pengecap Berbasis Diagram Vee. BIODIK: 
Jurnal IImiah Pendidikan Biologi, 6(200-213).

Rustaman, N. (2005). Strategi Belajar Mengajar Biologi. Universitas Negeri Malang.

Society of Biology. (2010). The Importance of Practical Biology: from School to Higher Education.

Sugiyono. (2012). Memahami Penelitian Kuantitatif, Kualitatif, dan R\&D. Alfabeta.

Supriatno, B. (2013). Pengembangan Program Perkuliahan Pengembangan Praktikum Biologi Sekolah Berbasis ANCORB untuk Mengembangkan Kemampuan Merancang dan Mengembangkan Desain Kegiatan Laboratorium. http://repository.upi.edu/id/eprint/3661

Supriatno, B. (2009). Uji Langkah Kerja Laboratorium Sekolah. Proseding Seminar Nasional Biologi: Inovasi Dan Pendidikan Biologi Dalam Pengembangan Sumber Daya Manusia, 255-261.

Wahidah, N. S., Supriatno, B., \& Kusumastuti, M. N. (2018). Analisis Struktur dan Kemunculan Tingkat Kognitif pada Desain Kegiatan Laboratorium Materi Fotosintesis. Assimilation: Indonesian Journal of Biology Education, 1(2), 70-76. https://doi.org/https://doi.org/10.17509/aijbe.v1i2.13050 